\title{
Chemically mimicked hypoxia modulates gene expression and protein levels of the sodium calcium exchanger in HEK 293 cell line via HIF-1a
}

\author{
Sona Hudecova ${ }^{1}$, Lubomira Lencesova ${ }^{1,2}$, Lucia Csaderova ${ }^{2}$, Marta Sirova ${ }^{1}$, Dana \\ Cholujova $^{3}$, Martin Cagala ${ }^{1}$, Juraj Kopacek ${ }^{4}$, Dusan Dobrota ${ }^{5}$, Silvia Pastorekova ${ }^{2,4}$ \\ and Olga Krizanova ${ }^{1}$ \\ ${ }^{1}$ Institute of Molecular Physiology and Genetics, Center of Excellence for Cardiovascular Research, Slovak Academy \\ of Sciences, Bratislava, Slovak Republic \\ 2 Molecular Medicine Center, Slovak Academy of Sciences, Bratislava, Slovak Republic \\ ${ }^{3}$ Cancer Research Institute, Slovak Academy of Sciences, Bratislava, Slovak Republic \\ ${ }^{4}$ Institute of Virology, Center of Excellence for Cardiovascular Research, Slovak Academy of Sciences, Bratislava, Slovak \\ Republic \\ ${ }^{5}$ Jessenius Faculty of Medicine, Comenius University, Martin, Slovak Republic
}

\begin{abstract}
Up to now a little is known about the effect of hypoxia on the sodium calcium exchanger type 1 (NCX1) expression and function. Therefore, we studied how dimethyloxallyl glycine (DMOG), an activator and stabilizer of the hypoxia-inducible factor (HIF)-1 $\alpha$, could affect expression of the NCX1 in HEK 293 cell line. We also tried to determine whether this activation can result in the induction of apoptosis in HEK 293 cells. We have found that DMOG treatment for 3 hours significantly increased gene expression and also protein levels of the NCX1. This increase was accompanied by a decrease in intracellular $\mathrm{pH}$. Wash-out of DMOG did not result in reduction of the NCX1 mRNA and protein to original - control levels, although $\mathrm{pH}$ returned to physiological values. Using luciferase reporter assay we observed increase in the NCX1 promoter activity after DMOG treatment and using wild-type mouse embryonic fibroblast (MEF)-HIF- $1^{+/+}$and HIF-1-deficient MEF-HIF-1 $1^{-/}$cells we have clearly shown that in the promoter region, HIF-1a is involved in DMOG induced upregulation of the NCX1. Moreover, we also showed that an increase in the NCX1 mRNA due to the apoptosis induction is not regulated by HIF-1a.
\end{abstract}

Key words: Sodium-calcium exchanger — DMOG - Apoptosis

Abbreviations: AIK, apoptosis inducer kit; BCECF, 2',7'-Bis(2-carboxyethyl)-5(6)-carboxyflourescein; DMOG, dimethyloxallyl glycine; EMEM, Eagle's minimum essential medium; FBS, fetal bovine serum; HEK 293, Human embryonal kidney cells; HIF, hypoxia inducible factor; HRE, hypoxia responsive element; MEF, mouse embryonic fibroblasts; MRPL19, mitochondrial ribosomal protein L19; NCX, $\mathrm{Na}^{+} / \mathrm{Ca}^{2+}$ exchanger; NF- $\kappa \mathrm{B}$, nuclear factor kappa B; PHD, prolyl hydroxylase; PBS, phosphate-buffered saline; PMSF, phenylmethylsulfonylfluoride; RT-PCR, reverse transcription polymerase chain reaction; SDS, sodium dodecylsulphate; TBS-T, Trisbuffered saline with Tween 20; TNFa, tumor necrosis factor $\alpha$.

Correspondence to: Olga Krizanova, Institute of Molecular Physiology and Genetics, Center of Excellence for Cardiovascular Research, Slovak Academy of Sciences, Vlarska 5, 83334 Bratislava, Slovak Republic

E-mail: olga.krizanova@savba.sk 


\section{Introduction}

The sodium calcium exchanger (NCX), a 9-transmembrane protein able to couple the efflux/influx of calcium to the influx/efflux of sodium ions by operating in a bidirectional way, is the major regulator of sodium and calcium homeostasis. Up to now, three types of the NCX were cloned, NCX1, 2 and 3 (Li et al. 1994; Nicoll et al. 1996). NCX1 is the most widespread type, occurring almost in all cells. Under physiological conditions, its primary role is to extrude calcium through a forward mode of operation in response to a depolarization, or to an increase in intracellular calcium concentration coupled to receptor stimulation. However, during some pathophysiological conditions, such as hypoxia, NCX is also able to operate in the reverse mode, thus extruding sodium ions while promoting calcium influx (Eigel et al. 2004; Molinaro et al. 2008).

NCX1 gene expression can be regulated by several agents. Retinoic acid upregulates NCX1 gene expression in the brain and heart (Hudecova et al. 2004a), probably via retinoic acid responsive element, or activator protein 2. NCX1 mRNA levels were significantly increased in skeletal muscle of hyperthyroid compared to euthyroid rats, indicating involvement of thyroid hormones in the transcriptional regulation of the NCX gene in this tissue (Hudecova et al. 2004b). Also, it was shown that nuclear factor kappa $\mathrm{B}(\mathrm{NF}-\kappa \mathrm{B})$-dependent NCX1 upregulation may play a fundamental role in calcium refilling of the endoplasmic reticulum, thus helping neurons to prevent endoplasmic reticulum stress during oxygen and glucose deprivation (Sirabella et al. 2009).

In our previous studies we have shown that short-term hypoxia ( $8 \%$ oxygen for 6 hours) significantly increased gene expression and protein levels of the NCX1 in rat cardiomyocytes (Hudecova et al. 2007). Hypoxia is a state of insufficient oxygen supply of the tissue or cell. Hypoxiainducible factor (HIF) is a key regulator of responses to hypoxia, occupying a central position in oxygen homeostasis in a wide range of organisms (Semenza 2000). Among its transcriptional targets are genes with critical roles in angiogenesis, erythropoiesis, energy metabolism, vasomotor function and apoptotic/proliferative responses (Correia and Moreira 2010). HIF is essential for normal development and plays a key role in pathophysiological responses to ischemia/hypoxia as well as in tumor growth and angiogenesis. Hypoxia-induced tolerance through the activation of the HIF-1 $\alpha$ is one major pathway involved in the neuroprotection (Siddiq et al. 2008). HIF-1 $\alpha$ is stabilized and heterodimerizes with HIF- $1 \beta$ to form HIF-1, subsequently regulating the expression of target genes (Fan et al. 2009). HIF-1 $\alpha$ is stabilized and activated by hypoxia and hypoxia/mimetic agents, such as iron chelators desferoxamine, clioquinol, dimethyloxallyl glycine (DMOG), etc. and modulates the expression of several protective target genes, including glucose transporters, glycolytic enzymes and angiogenic factors (Semenza 2000). Studies have shown that HIF-1 $\alpha$ protein levels increased immediately after the hypoxic exposure, peaked at 3-4 hours after hypoxic-ischemic injury and the elevated level of HIF-1a persisted up to $24 \mathrm{~h}$ after the insult (Calvert et al. 2006). Recently it was shown that NCX1 gene is a novel HIF-1 target (Valsecchi et al. 2011).

Nevertheless, in the promoter region of the NCX1, no hypoxia responsive element (HRE), which binds HIF-1, was found. However, in the position -337 to -349 bp from the transcriptional beginning, NF- $\kappa \mathrm{B}$ transcription factor occurs. Cummins and coworkers (2006) found that hypoxia activates NF- $\kappa B$ through the pathway involving activation of I $\mathrm{B}$ kinase- $\beta$ (IKK $\beta$ ) leading to phosphorylation-dependent degradation of $I \kappa B \alpha$ and liberation of NF- $\kappa B$. Furthermore, through increasing the pool and/or activation potential of IKK $\beta$, hypoxia amplifies cellular sensitivity to stimulation with tumor necrosis factor alpha (TNFa). Within its activation loop, IKK $\beta$ contains an evolutionarily conserved LxxLAP consensus motif for hydroxylation by prolyl hydroxylases (PHDs). Mimicking hypoxia by treatment of cells with siRNA against PHD-1 or PHD-2 or the pan-prolyl hydroxylase inhibitor DMOG results in NF- $\mathrm{KB}$ activation.

In order to clarify how the hypoxia affects gene expression of the NCX1, we used DMOG as an inhibitor of PHD activity and study the gene expression, protein levels, calcium transport activity and NCX1 promoter region activity. We also tried to determine, whether DMOG-induced NCX1 upregulation can result in the development of apoptosis. For these experiments, we used human embryonic kidney 293 cells (HEK 293), since these cells express NCX1 and are a good model for molecular studies.

\section{Materials and Methods}

\section{HEK 293 cells and mouse embryonic fibroblasts (MEF)}

HEK 293 cell line was obtained from German Collection of Microorganisms and Cell Cultures (Braunschweig, Germany). The cells were grown in $10 \mathrm{ml}$ flasks and/or 6-wells plates in Eagle's Minimum Essential Medium (EMEM) with $1 \mathrm{mg} / \mathrm{ml}$ L-glutamine (Biochrom AG, Germany), supplemented with $10 \%$ fetal bovine serum (FBS; Biochrom AG, Germany) and mixture of streptomycin and penicillin (both from Calbiochem, Merck Biosciences, Germany) in a humified atmosphere of $5 \% \mathrm{CO}_{2}$ air at $37^{\circ} \mathrm{C}$.

To analyze whether HIF-1 $\alpha$ is also involved in the upregulation of the NCX1 gene expression, we treated wildtype mouse embryonic fibroblast (MEF)-HIF- $1^{+/+}$and HIF-1-deficient MEF-HIF-1 ${ }^{-/-}$cells with DMOG and/or apoptosis inducer kit I (AIK; Calbiochem, Merck Bio- 
sciences, Germany). Both these cells were a generous gift of Dr. Doerthe Katschinski from the University of Gottingen, Germany. MEFs were derived from mouse day 9.5 embryos, either wild-type (MEF-HIF- ${ }^{+/+}$) or deficient (MEF-HIF$1^{-/-}$) for HIF-1, immortalized with SV40 large T antigen and transformed with H-ras (Ryan et al. 2000; Seagroves et al. 2001). All cell lines were cultured in Dulbecco's modified Eagle's medium (high glucose; Biochrom AG, Germany) as described in Katschinski et al. (2002).

\section{Treatment with DMOG, wash-out and induction of apop- tosis}

To HEK 293 cells, DMOG (Cayman Chemical Company, USA) in the final concentration $50 \mu \mathrm{M}$ was added for 3 hours. For wash-out, medium with DMOG was exchanged by new EMEM with 10\% FBS and cells were grown in standard conditions described above for additional three hours. AIK was added to induce apoptosis in HEK 293 cells in the dilution $1: 1000$, as recommended by the provider. AIK is composed of following inducers - actinomycin D, camptothecin, cycloheximide, dexamethasone and etoposide. Apoptosis was induced for 3 hours, afterwards cells were used for RNA isolation, immunofluorescence, or Western blot analysis. In order to study whether DMOG and AIK might have an additive effect, both these solutions were added to cells simultaneously and cells were incubated for 3 hours.

\section{$R N A$ preparation and relative quantification of $m R N A$ levels by RT-PCR}

Population of total RNAs was isolated by TRI Reagent (MRC Ltd., USA). Briefly, cells were scraped and homogenized by pipette tip in sterile water and afterwards TRI Reagent was added. After 5 minutes the homogenate was extracted by chloroform. RNAs in the aqueous phase were precipitated by isopropanol. RNA pellet was washed with $75 \%$ ethanol and stored in $96 \%$ ethanol at $-70^{\circ} \mathrm{C}$. The purity and integrity of isolated RNAs was checked on GeneQuant Pro spectrophotometer (Amersham Biosciences, UK). Reverse transcription was performed using $1.5 \mu \mathrm{g}$ of total RNAs and Ready-To-Go You-Prime First-Strand Beads (GE Healthcare-Life Sciences) with pd(N6) primer. PCR specific for the type NCX1 (Gene ID: 6546) was carried out afterwards using primers NCX1: $5^{\prime}$ AGG CGG CTT CTC TTT TAC-3' and NCX2: $5^{\prime}$-CGA CTT CCA AAA CCA GAC-3'. MRPL19 was used as a housekeeper gene control for semi-quantitative evaluation of PCR. Following primers for MRPL19 were used: MRPL1 5'-GGG ATT TGC ATT CAG AGA TCA G-3' and MRPL2 5'-GGA AGG GCA TCT CGT AAG-3' (Gene ID: 9801). Following primers for Caspase 3 and Bax were used: CaspA: 5'-AAC TGG ACT GTG GCA TTG-3'; CaspB: 5'-ACC AGG TGC TGT GGA GTA-3'; (Gene ID: 158256109); Baxa: 5'-AGA GGA TGA
TTG CCG CCG-3'; Baxb: 5'-CAA CCA CCC TGG TCT TGC ATC-3'; PCR specific for NCX1 started by initial denaturation at $94^{\circ} \mathrm{C}$ and was followed by 30 cycles of denaturation at $94^{\circ} \mathrm{C}$ for $1 \mathrm{~min}$, annealing at $48^{\circ} \mathrm{C}$ for $1 \mathrm{~min}$ and polymerization at $72^{\circ} \mathrm{C}$ for $1 \mathrm{~min}$. PCR specific for MRPL19, Caspase 3 and Bax started by initial denaturation at $94^{\circ} \mathrm{C}$ and was followed by 30 cycles of denaturation at $94^{\circ} \mathrm{C}$ for $1 \mathrm{~min}$, annealing at $60^{\circ} \mathrm{C}$ for $1 \mathrm{~min}$ and polymerization at $72^{\circ} \mathrm{C}$ for $1 \mathrm{~min}$. PCRs were terminated by final polymerization at $72^{\circ} \mathrm{C}$ for $7 \mathrm{~min}$. Products were analyzed in $2 \%$ agarose gels and signals were evaluated by PCBAS 2.0 software. NCX1 gene expression was evaluated semiquantitatively relatively to the housekeeper MRPL19 and displayed as arbitrary units (a.u.).

\section{Western blot analysis}

NCX protein was determined in the crude membrane fraction from the cells. Cells were scraped and resuspended in 10 $\mathrm{mM}$ Tris- $\mathrm{HCl}, \mathrm{pH}$ 7.5, $1 \mathrm{mM}$ phenylmethyl sulfonylfluoride (PMSF, Serva, Germany) and subjected to centrifugation for $10 \mathrm{~min}$ at $10000 \times g$ and $4^{\circ} \mathrm{C}$. The pellet was resuspended in Tris-buffer containing the $50 \mu \mathrm{M}$ CHAPS (3-[(3Cholamidopropyl)dimethyl-ammonio] 1-propanesulfonate, Sigma, USA), and afterwards incubated for $10 \mathrm{~min}$ at $4^{\circ} \mathrm{C}$. The lysate was centrifuged for $10 \mathrm{~min}$ at $10000 \times g$ at $4^{\circ} \mathrm{C}$. Protein concentration of supernatants was determined by the method of Lowry (Lowry et al. 1951). $30 \mu \mathrm{g}$ of protein extract from each sample was separated by electrophoresis on $10 \%$ SDS polyacrylamide gels and proteins were transferred to Hybond-P membrane using semidry blotting (Owl, Inc., USA). Membranes were blocked in 5\% non-fat dry milk in Tris-buffered saline with Tween 20 (TBS-T) overnight at $4^{\circ} \mathrm{C}$ and then incubated for $1 \mathrm{~h}$ with the mouse monoclonal antibody to NCX1 (Abcam, Cambridge, UK), diluted $1: 1000$. This antibody recognizes a $120 \mathrm{kDa}$ protein. Horseradish peroxidase linked secondary antibody and chemiluminiscence detection system (ECL Plus, Amersham Biosciences, UK) was used for visualization. Each membrane was digitally captured using an imaging system (Kodak Imaging Station 440 CF, Rochester, NY, USA). Optical density of individual bands was quantified using PCBAS 2.0 software.

\section{Immunofluorescence}

HEK 293 cells were plated on poly-L-lysine (Sigma-Aldrich, St. Louis MD, USA) coated $(10 \mathrm{mg} / \mathrm{ml})$ coverslips in Sarstedt 24-well plates in $0.5 \mathrm{ml}$ of EMEM with $10 \%$ of FBS and mixture of streptomycin and penicillin (Calbiochem, Merck Biosciences, Germany). Cells were incubated in a humidified atmosphere of $5 \% \mathrm{CO}_{2}$ air at $37^{\circ} \mathrm{C}$. After the treatment procedures, cells were fixed in ice-cold methanol. Non-specific binding was blocked by incubation with phosphate-buffered saline (PBS) containing 1\% BSA (Merck Biosciences, Ger- 
many) for $30 \mathrm{~min}$ at $37^{\circ} \mathrm{C}$. Then, cells were incubated with primary antibodies diluted $1: 1000$ for $60 \mathrm{~min}$ at $37^{\circ} \mathrm{C}$. We used primary mouse monoclonal antibody to NCX1 (Abcam, Cambridge, UK), coverslips were washed in PBS and incubated with CFTM488 goat anti-mouse IgG $(\mathrm{H}+\mathrm{L})$ (Biotium, Hayward, CA, USA) secondary antibody for $60 \mathrm{~min}$ at $37^{\circ} \mathrm{C}$. Finally, the cells were mounted onto slides in a mounting medium with Citifluor (Agar Scientific, UK).

Images were taken at LSM 510 Meta microscope (Zeiss), magnification $63 \times$, at the same camera and microscope setup. Program ImageJ (National Institute of Health, USA) was used for image processing. Ten cells were selected for each sample, and intensity histogram and the resulting intensity per pixel was calculated. The results in the graph give mean intensity per pixel for each sample (mean $\pm \mathrm{SD}, n=10$, $p<$ 0.01 and $p<0.05$, respectively).

\section{Detection of apoptosis with Annexin-V-Fluos}

HEK 293 cells were trypsinized, washed with PBS and pelleted $200 \times g$ for $5 \mathrm{~min}$. Cell pellet from each well was resuspended in $100 \mu$ l of Annexin-V-Fluos labeling solution and incubated at room temperature in dark for 20 minutes. Labeling solution included incubation buffer with $10 \mathrm{mM}$ HEPES/NaOH $(\mathrm{pH}$ 7.4), $140 \mathrm{mM} \mathrm{NaCl}$ and $5 \mathrm{mM} \mathrm{CaCl}_{2}, 2 \mu \mathrm{l}$ of Annexin-V-Fluos (Roche Diagnostics, Germany), and $0.02 \mu$ g propidium iodide. After the incubation was completed, cells were washed with $5 \mathrm{ml}$ of PBS, pelleted at $200 \times g$ for $5 \mathrm{~min}$, suspended in $300 \mu \mathrm{l}$ of PBS and measured on Epics Altra flow cytometer (Beckman Coulter, Fullerton, CA, USA).

\section{Measurement of pHi by fluorescence probe}

Intracellular $\mathrm{pH}(\mathrm{pHi})$ was measured using the fluorescent probe 2',7'-biscarboxyethyl-5,6-carboxyfluorescein (BCECF; Sigma Aldrich, USA). Cells plated onto 6-well plates were loaded with $8.2 \mu \mathrm{M}$ BCECF and $5 \%$ pluronic acid in PBS buffer, $\mathrm{pH} 7.48$ for 30 minutes at $37^{\circ} \mathrm{C}, 5 \% \mathrm{CO}_{2}$, in dark. Afterwards, cells were washed with PBS buffer and calibration was performed using PBS/HEPES buffers with different $\mathrm{pH}$ values $(7.51 ; 7.48 ; 7.03 ; 6.52)$. The fluorescence was excited at $489 \mathrm{~nm}$ and measured at $525 \mathrm{~nm}$ on the fluorescence scanner BioTek (Germany). The pHi signal was calibrated to $\mathrm{pHo}$ by adding $10 \mu \mathrm{M}$ nigericin (Sigma Aldrich, USA) with $130 \mathrm{mM}$ $\mathrm{KCl}$. These values were used for the calibration curve, from which $\mathrm{pHi}$ values were calculated for samples.

\section{NCX transport in HEK 293}

NCX transport was measured in ghosts prepared from HEK 293 cells. Plated cells were washed for $3 \mathrm{~min}$ with hypotonic cell solution ( $0.1 \mathrm{mM} \mathrm{MgCl}_{2}$ and $3 \mathrm{mM}$ HEPES, $\mathrm{pH} 7.4$ ) and then isotonic cell solution was added with Fluo-3AM
(Invitrogen) and calcium ( $1 \mathrm{mM} \mathrm{MgCl}_{2}, 10 \mathrm{mM}$ HEPES ( $\mathrm{pH}$ 7.4), $10 \mathrm{mM}$ glucose, $\mathrm{CaCl}_{2}$ to the final concentration of $500 \mu \mathrm{M}$, Fluo-3 AM to the final concentration of $8 \mu \mathrm{M}$ and pluronic acid to $0.04 \%$ ). After $10 \mathrm{~min}$ of loading in the dark at room temperature, cells were washed with isotonic cell solution and solution of $5 \mathrm{mM} \mathrm{KCl} / 140 \mathrm{mM} \mathrm{NaCl}$ was added. The fluorescence signal was measured on fluorescence reader BioTek at $37^{\circ} \mathrm{C}$. Excitation was measured at $485 \mathrm{~nm}$ and emission at $528 \mathrm{~nm}$. Calcium transport was calculated from the difference in fluorescent signal between $\mathrm{KCl}$ and $\mathrm{NaCl}$ solution. The control of fluorescent signal was performed by adding of $10 \%$ SDS and $50 \mathrm{mM}$ EGTA $\mathrm{pH} 7.4$ on the end of measurements. Calcium transport was expressed as fluorescent arbitrary units.

\section{Promoter activity measured by luciferase assay}

A promoter fragment for NCX1 was obtained from DNA isolated from the rat brain by PCR using specific primers: NCX1-F: 5'-AAAAACGCGTatcagggagtgttgctaggc-3' and NCX1-R: 5'-AAAACTCGAGtctggacacaggtcaaggact-3' with annealing temperature $60^{\circ} \mathrm{C}$ (Gene ID: 29715). These primers amplified $863 \mathrm{bp}$ fragment from the specific NCX1 promoter region. Afterwards, amplified fragment was analyzed on $1.2 \%$ agarose gel, bands were cut out and cleaned using Wizard SV Gel and PCR Clean-Up System (Promega, Wisconsin, USA). $150 \mathrm{ng}$ of the cleaned fragment was cleaved by restriction endonucleases MluI and XhoI (Fast Digest) (Fermentas, Lithuania). Also, $1 \mu \mathrm{g}$ of the Luciferase Reporter vector pGL3 was cleaved. The cleaving was verified on $0.8 \%$ agarose gel. The cleaved fragment was then ligated into 100 ng of the vector using T4 ligase and transformed into JM 109 competent cells. The cells were than sown on Petri dish with $\mathrm{LB}$ medium + agar with ampicillin and grown at $37^{\circ} \mathrm{C}$ for overnight. Separate colonies of bacteria were transferred to fresh dish and grown again at $37^{\circ} \mathrm{C}$ for overnight and afterwards screened for transformed fragment. Selected colonies that contain transformed fragment were transferred to LB medium and grown. Then, plasmid DNA was isolated using Pure Yield Plasmid Miniprep System (Promega, USA), concentration of DNA was measured and plasmid was cleaved by MluI and XhoI for 1 hour at $37^{\circ} \mathrm{C}$. Finally, HEK 293 cells were transfected and let grown for overnight at $37^{\circ} \mathrm{C}$. Next day, cells were divided into four groups, influenced by DMOG, AIK and combination as described earlier. Luciferase activity was measured using Dual Luciferase Reporter Assay (Promega, USA) and measured on luminometer (BioTek, USA).

\section{Results}

DMOG treatment for $3 \mathrm{~h}$ significantly increased mRNA (Fig. 1A) and protein (Fig. 1B) levels of the NCX1 compared 

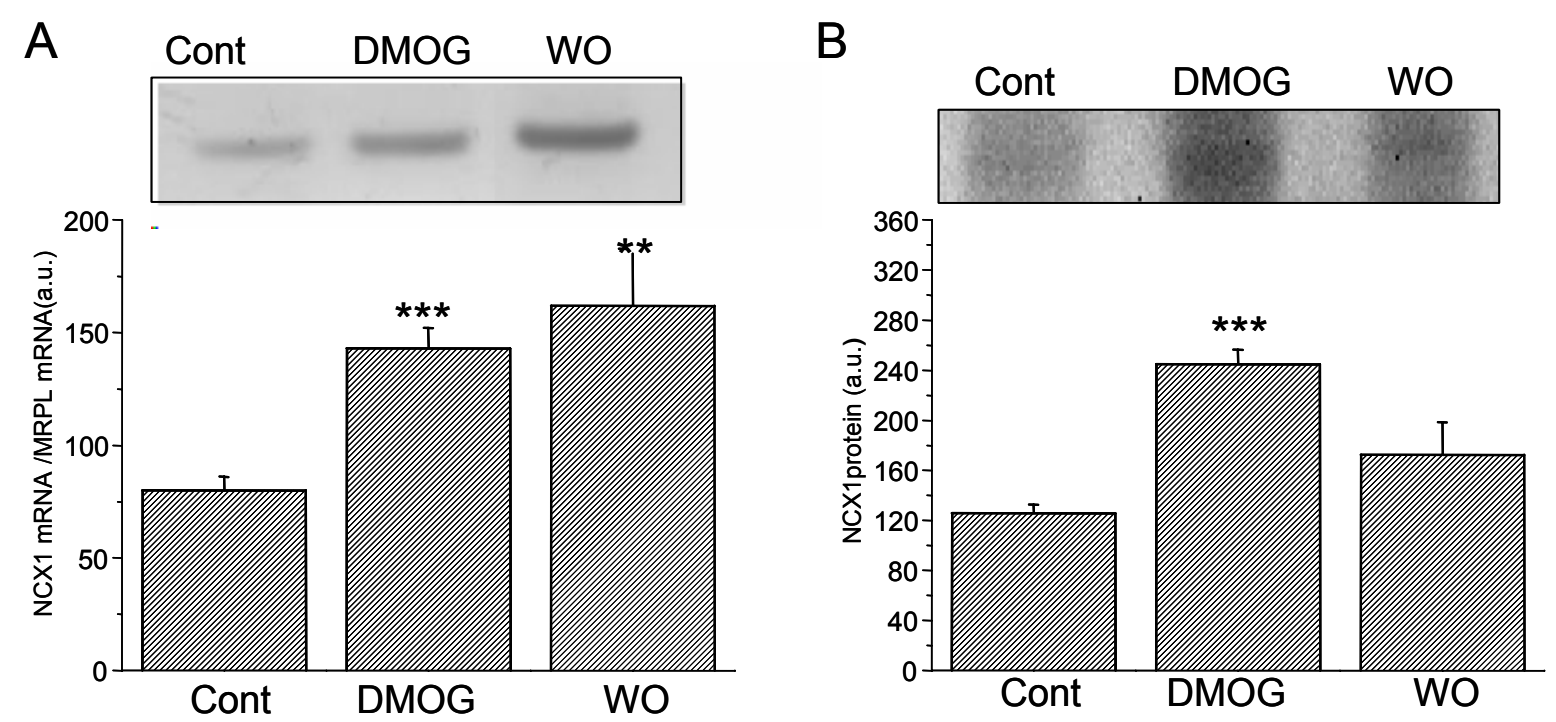

Figure 1. The mRNA (A) and protein (B) levels of the NCX1 in HEK 293 cells after DMOG treatment for 3 hours (DMOG) and subsequent wash-out of DMOG for additional 3 hours (WO). NCX1 mRNA was quantified relatively to the housekeeper MRPL19. Both, mRNA and protein levels of the NCX1 were elevated in cells exposed to DMOG treatment for 3 hours. The mRNA levels of the NCX1 after washout of DMOG were still significantly increased compared to control cells (Cont). Nevertheless, protein levels of the NCX1 did not show a significant increase after wash-out. Each column is displayed as mean \pm S.E.M. and represents an average of 5 independent cultivations. Statistical significance was calculated by one-way ANOVA and $t$-test modified by Bonferroni's correction. ${ }^{* *} p<0.01,{ }^{* *} p<0.001$.

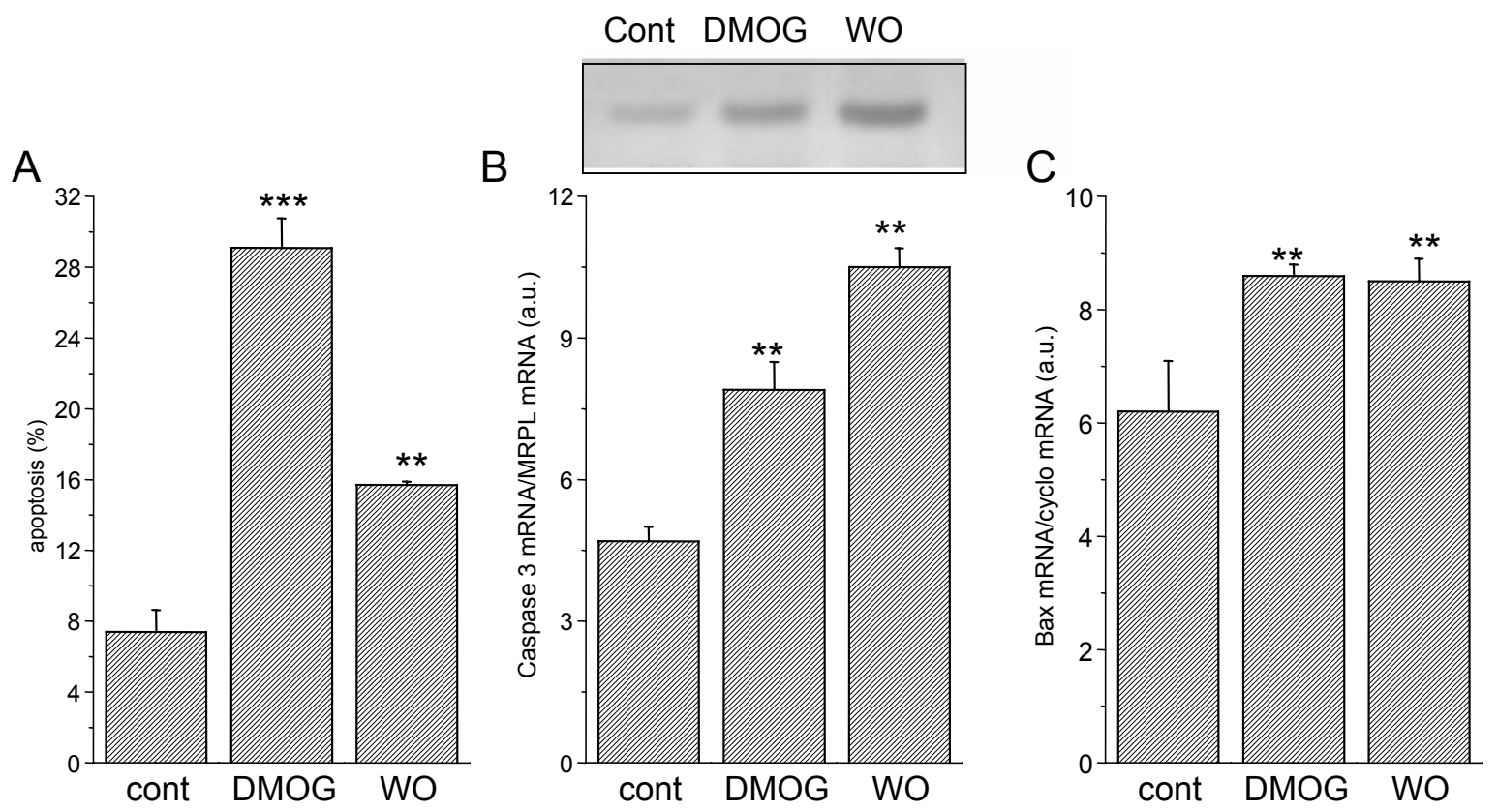

Figure 2. The amount of apoptotic cells (A), caspase 3 mRNA levels (B) and Bax mRNA levels (C) in HEK 293 cells after DMOG treatment for 3 hours (DMOG) and subsequent wash-out of DMOG for additional 3 hours (WO). Comparison of the amount of apoptotic cells was measured by the binding of Annexin-V-Fluos to HEK 293 cells (A). DMOG significantly elevated amount of apoptotic cells compared to control cells. This elevation was lower after the wash-out of DMOG for 3 hours, although still significantly higher as in control. As a second, independent experiment verifying induction of apoptosis by DMOG treatment, gene expression of the apoptotic marker caspase 3 (B) and Bax (C) was measured. The mRNA of caspase 3 and also Bax was elevated in DMOG and also in wash-out cells. Each column is displayed as mean \pm S.E.M. and represents an average of 3 independent cultivations. Statistical significance was calculated by one-way ANOVA and $t$-test modified by Bonferroni's correction. ${ }^{* *} p<0.01,{ }^{* * *} p<0.001$. 
to control, untreated cells. When DMOG was washed-out (WO), no significant changes in the NCX1 mRNA were observed compared to mRNA levels in DMOG-treated cells $3 \mathrm{~h}$ after the end of hypoxia (Fig. 1A) and these levels were still significantly increased compared to control cells. Protein levels were also increased after the wash-out of DMOG compared to controls (Fig. 1B), although this increase was not so pronounced as in mRNA. DMOG treatment elevated percentage of the apoptotic cells compared to control cells (Fig. 2A). Number of apoptotic cells was also increased in cells subjected to DMOG treatment and subsequent wash-out of DMOG, although not to such extend than after DMOG treatment (Fig. 2A). Since we proposed that certain number of apoptotic cells was removed by the wash-out, we determined mRNA of two additional proapoptotic proteins - caspase 3 and Bax. Both, caspase 3 mRNA and Bax mRNA were markedly elevated in DMOG and also in WO cells (Fig. 2B,C). In accordance, immunofluorescence with antibody against NCX1 showed stronger signal in DMOG-treated cells and cells subjected to DMOG and subsequent wash-out of DMOG (WO) compared to control cells (Cont; Fig. 3). Specificity of the antibody was verified by negative control (NC), where primary antibody was not used. After the wash-out of DMOG for three hours, pHi returns to control, physiological values in HEK 293 cells (Fig. 4A). Induction of apoptosis for three hours by AIK decreased pHi similarly to DMOG treatment for three hours (Fig. 4B). Protein levels of the NCX1 were significantly increased after the exposure to DMOG or AIK stimuli for three hours (Fig. $5 \mathrm{~A})$. Combined effect of both, DMOG and apoptotic stimulus did not reveal any additional increase, neither in NCX1
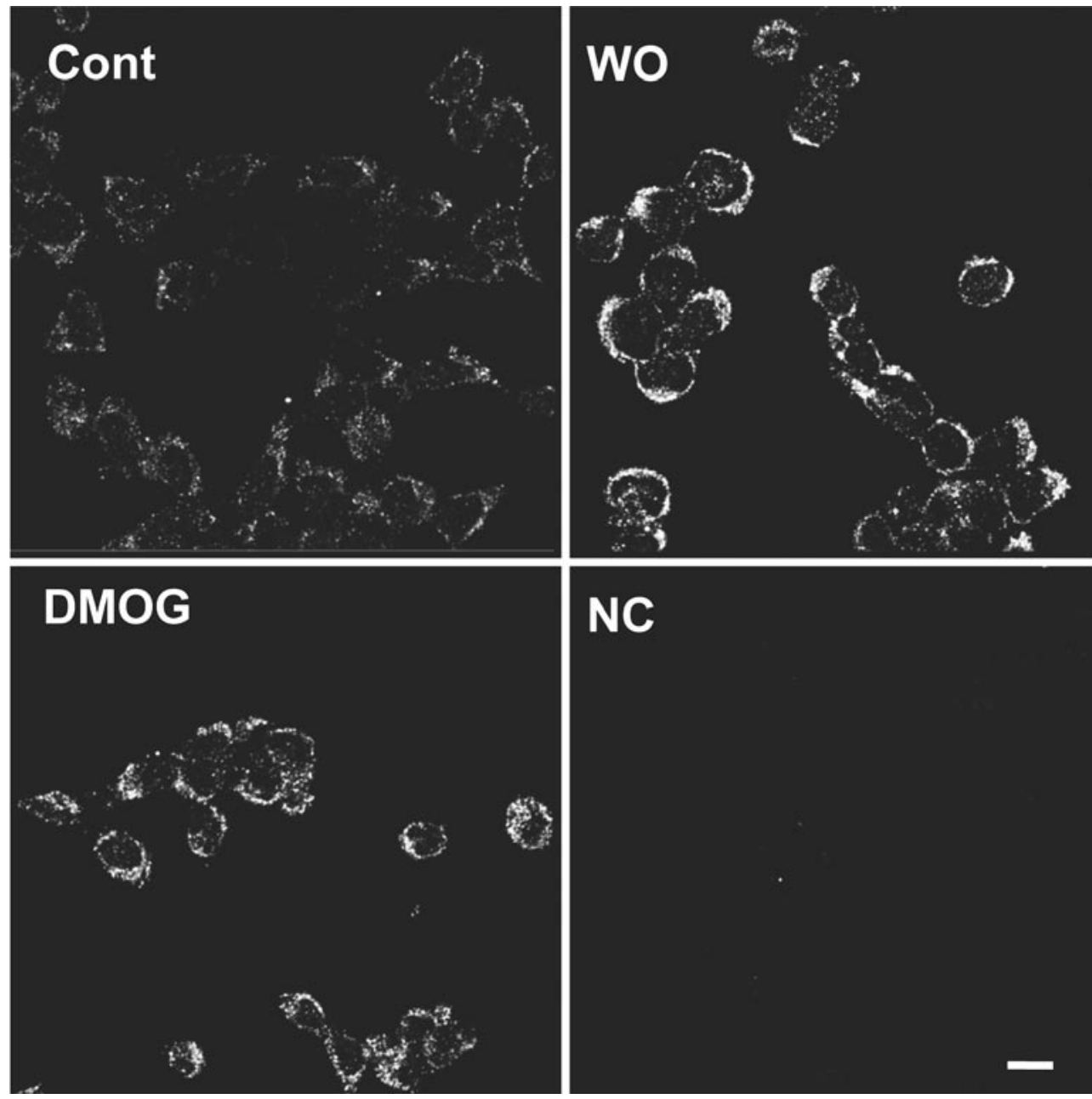

Figure 3. Immunofluorescence of HEK 293 cells after DMOG treatment (DMOG) and subsequent wash-out of DMOG for $3 \mathrm{~h}$ (WO). Immunofluorescent staining was performed using primary antibody against NCX1 and fluorescently labeled secondary antibody. As a control (Cont), untreated cells were used. Negative control (NC) was performed without primary antibody. NCX1 signal was stronger in DMOG and WO, compared to Cont. Also, in WO, change in the shape of cells is visible, compared to Cont and also to DMOG. Scale bar represents $10 \mu \mathrm{m}$. 
A

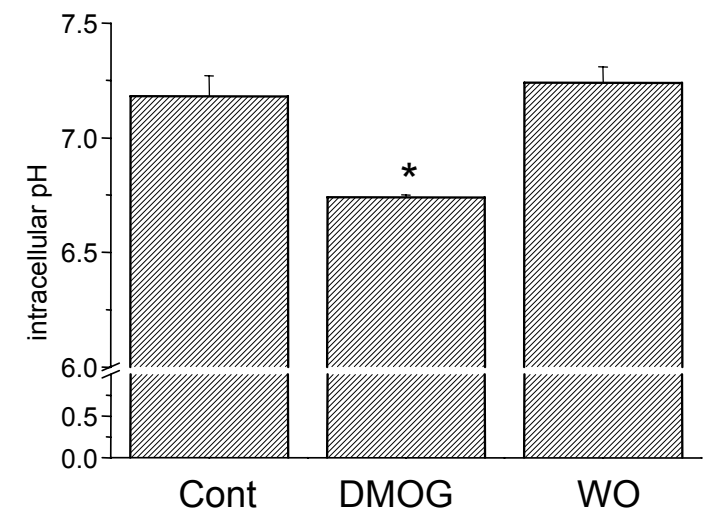

B

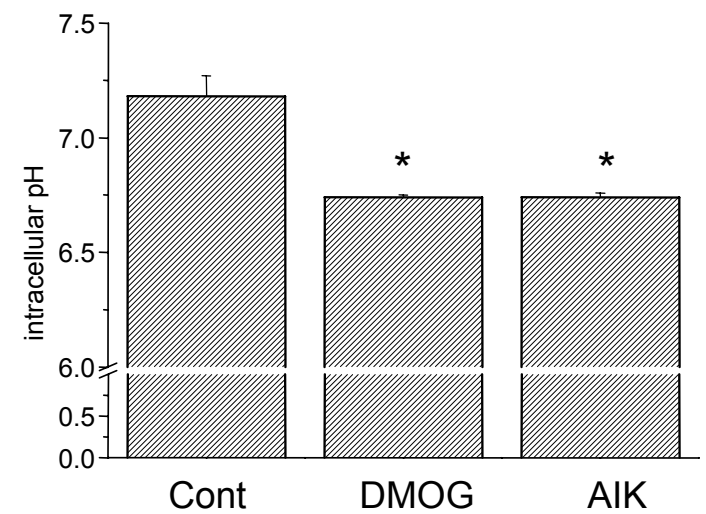

Figure 4. Changes in pHi in HEK 293 cells after 3 hours of DMOG treatment (DMOG) with subsequent 3 hours of wash-out of DMOG (WO; A) and after 3 hours of induced apoptosis (AIK; B). pHi decreases, when cells were exposed to DMOG for 3 hours. Wash-out of DMOG for additional 3 hours restored pHi values to the control levels. AIK showed the same effect as DMOG. Each column is displayed as mean \pm S.E.M. and represents an average of 3 independent cultivations. Statistical significance was calculated by one-way ANOVA and $t$-test modified by Bonferroni's correction. ${ }^{*} p<0.05,{ }^{* * *} p<0.001$.

A

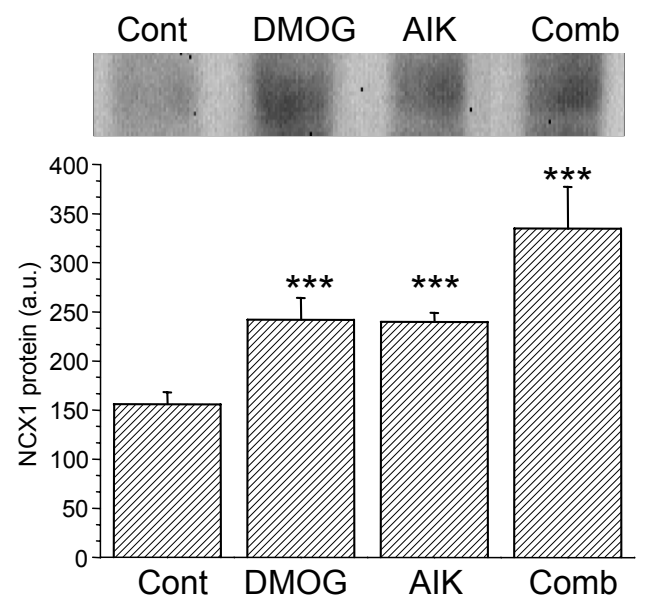

B

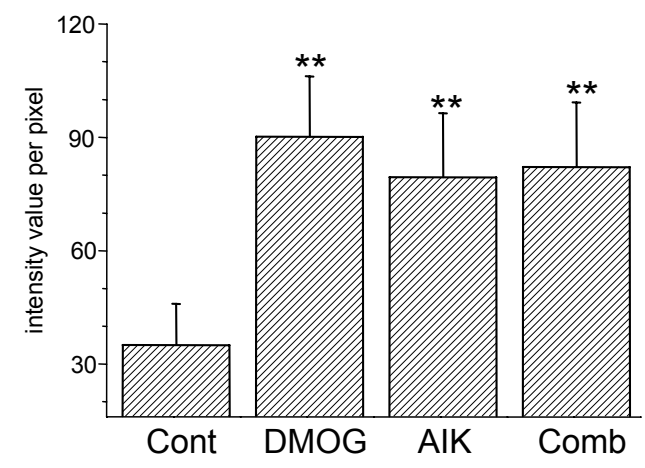

C
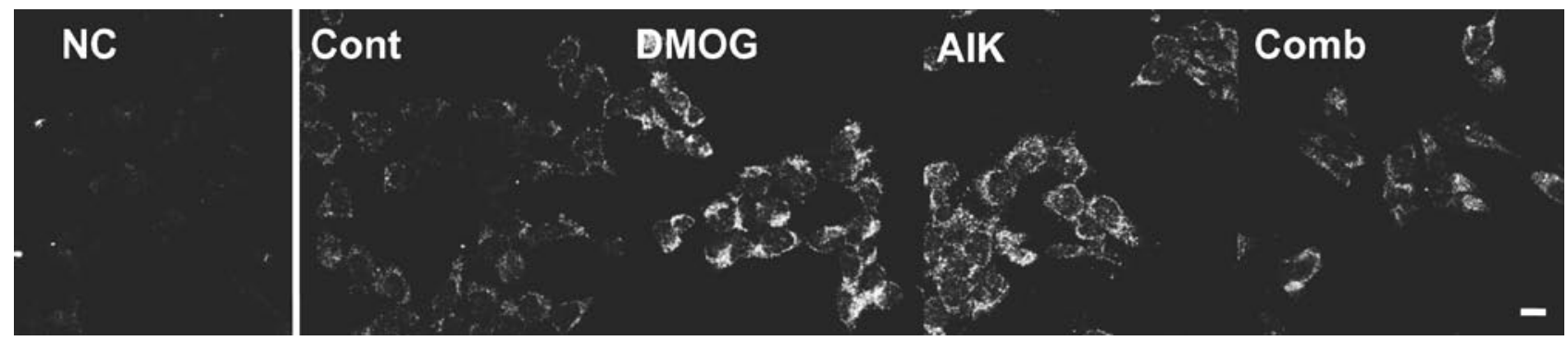

Figure 5. Protein expression of the NCX1 in HEK 293 cells exposed to DMOG for 3 hours (DMOG), apoptosis inducers kit for 3 hours (AIK) and combination of both factors (Comb) detected by Western blot analysis (A) and by immunofluorescence (B, C). 3 hours of DMOG treatment and 3 hours of induced apoptosis showed by both methods the same effect of elevation of NCX1 protein in the cells. Combination of DMOG and apoptosis caused also significant elevation of NCX1 protein compared to control cells (Cont). Each column is displayed as mean \pm S.E.M. Statistical significance was calculated by one-way ANOVA and $t$-test modified by Bonferroni's correction. ${ }^{\star *} p<0.01,{ }^{* * *} p<0.001$. Scale bar, $10 \mu \mathrm{m}$. 
A

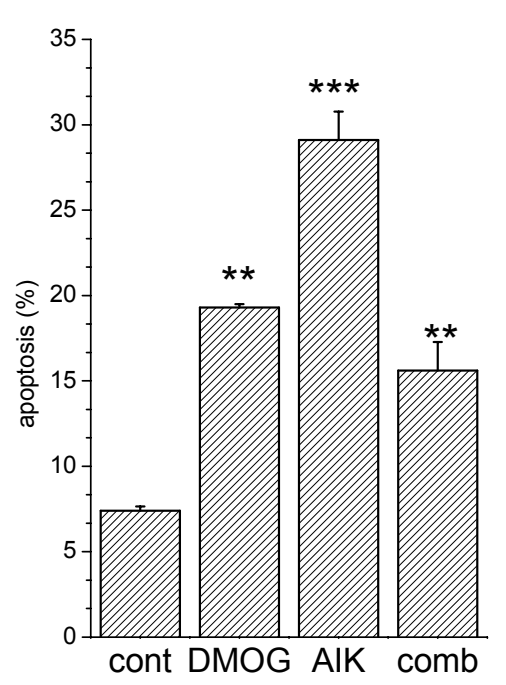

B

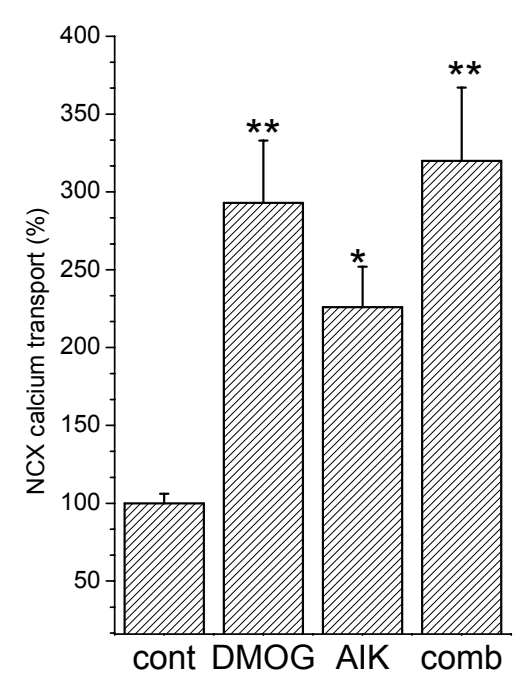

C

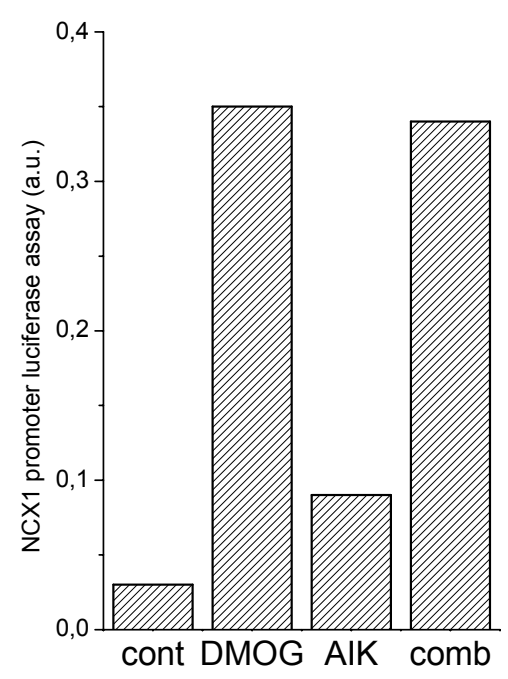

Figure 6. NCX1 apoptosis (A), calcium transport (B) and promoter activity (C), in DMOG-treated cells for 3 h (DMOG), AIK-treated cells for $3 \mathrm{~h}(\mathrm{AIK})$ and their combination (Comb). NCX1 promoter activity was measured as luciferase activity using Dual Luciferase Reporter Assay and measured on luminometer. Comparison of the amount of apoptotic cells was measured by the binding of Annexin-VFluos to HEK 293 cells. AIK and DMOG increased promoter activity of NCX1. No synergistic increase was observed after the treatment with both these compounds. NCX transport was measured in ghosts prepared from HEK 293 cells. DMOG and AIK had the same effect on calcium transport as on promoter activity of NCX1. Calcium transport was expressed as fluorescent arbitrary units.

protein levels, nor in the intensity value per pixel and the immunofluorescence (Fig. 5B,C). However, when DMOG and AIK were added simultaneously, decrease in the percentage of apoptotic cells was observed compared to AIK-treated cells (Fig. 6A), although no significant difference was seen in calcium release through the NCX1 (Fig. 6B). DMOG treatment increased NCX1 promoter activity (Fig. 6C). When both these compounds were added simultaneously, increase identical to that seen in DMOG-treated cells was observed. In order to determine, whether DMOG and/or AIK-induced increase in NCX1 mRNA was due to HIF-1a, we compared the NCX1 expression in $\mathrm{MEF}^{+/+}$and $\mathrm{MEF}^{-/-}$cells (Fig. 7). After DMOG treatment, we observed significant increase in NCX1 mRNA in $\mathrm{MEF}^{+/+}$, but not in $\mathrm{MEF}^{-/-}$cells. Also, we have seen elevation in the gene expression of the NCX1 due to AIK induction. However, this increase occurs both, in $\mathrm{MEF}^{+/+}$ and $\mathrm{MEF}^{-/-}$cells (Fig. 7).

\section{Discussion}

We have found that DMOG treatment for 3 hours significantly increased gene expression and also protein levels of the NCX1 in HEK 293 cells. This elevation was accompanied with a decrease in the $\mathrm{pHi}$. Wash-out of DMOG for 3 hours did not result in a reduction of the NCX1 mRNA and protein to original, control levels, although $\mathrm{pH}$ returned to control values. Our results are in agreement with our previous studies (Hudecova et al. 2007), where we observed significant increase in NCX1 mRNA and protein in hypoxic cardiomyocytes. Moreover, upregulation of the NCX1 expression and activity observed in microglia after permanent middle cerebral artery occlusion suggests a relevant role of NCX1 in modulating microglia functions in the postischemic brain (Boscia et al. 2009).

We have shown that DMOG treatment significantly increased calcium transport through the NCX1. Accumulation of intracellular calcium in hypoxia was determined by several laboratories (Jurkovicova et al. 2007; Shono et al. 2010). Shono and coworkers also suggested that recovery from intracellular acidosis causes a transient increase in cytosolic $\mathrm{Ca}^{2+}$ due to reversal of calcium transport via NCX coactivated with $\mathrm{Na}^{+} / \mathrm{H}^{+}$exchanger, which can cause cell death.

Induction of apoptosis also causes increase in the NCX1 expression. Using luciferase assay and MEF cells we have shown that this increase is caused by different mechanism compared to hypoxia. Up to now, there are only few studies about the effect of apoptosis on NCX expression showing opposing results. In cardiomyocytes it was shown that NCX down-regulation and consequent increases in cytosolic and sarcoplasmic reticulum $\mathrm{Ca}^{2+}$ can lead to $\mathrm{Ca}^{2+}$ overloadinginduced loss of mitochondrial membrane potential (Miyamoto et al. 2005). On the other hand, SEA0400, a specific inhibitor of the $\mathrm{Na}^{+} / \mathrm{Ca}^{2+}$ exchanger, attenuates sodium 


\section{MEF +/+}

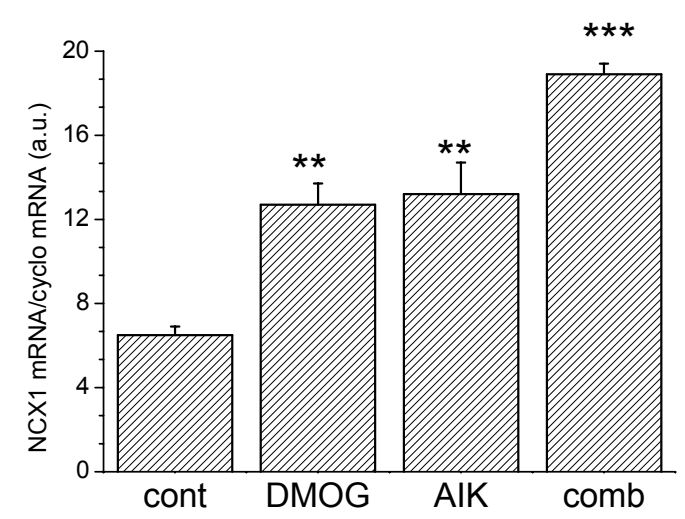

MEF-/-

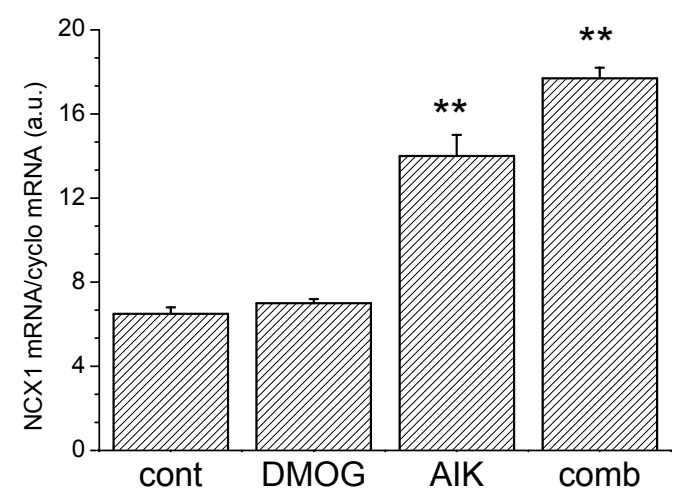

Figure 7. Effect of DMOG and/or AIK treatment on the NCX1 mRNA levels in $\mathrm{MEF}^{+/+}$and $\mathrm{MEF}^{-/}$cells. In $\mathrm{MEF}^{+/+}$cells DMOG significantly increased NCX1 mRNA levels compared to control, while in $\mathrm{MEF}^{-/-}$cells, no difference was visible in mRNA levels of the NCX1 in control and DMOG-treated groups. This result points to the involvement of HIF-1 $\alpha$ in DMOG-induced increse of NCX1 mRNA. Since increase of the NCX1 mRNA in AIK-treated cells was the same in $\mathrm{MEF}^{+/+}$and the $\mathrm{MEF}^{-/-}$cells, we propose that AIK-induced increase of the NCX1 mRNA is not caused by HIF-1 1 . Results are displayed as mean \pm S.E.M. and represents and average of nine measurements from 3 cultivations.

nitroprusside-induced apoptosis in cultured rat microglia (Nagano et al. 2005).

Since DMOG is known to stabilize HIF-1a, one of the possible explanations would be the involvement of HRE element in the activation of the gene expression of NCX1. When we checked promoter region of the NCX up to -863 bp from the transcriptional beginning, we did not find any consensus sequence for HRE. Nevertheless, we found NF$\kappa \mathrm{B}$ consensus sequence in this promoter region. Hypoxia is known to activate NF- $\mathrm{B}$ (Taylor et al. 1998; Ryan et al. 2005). Hypoxia stimulated a (1.9 \pm 0.1$)$-fold and (5.9 \pm 1.7$)$-fold increase in basal NF- $\kappa \mathrm{B}$-dependent transcriptional activity at 24 and $48 \mathrm{~h}$, respectively, as measured by the NF- $\mathrm{kB}-$ dependent luciferase reporter assay (Cummins et al. 2006). Sirabella et al. (2009) have recently shown that in primary cortical neurons, transcript and protein expression of the 3 isoforms, NCX1, NCX2 and NCX3 respond differently to anoxic injury. In particular, 3 hours of oxygen and glucose deprivation induced an NF- $\kappa \mathrm{B}$-dependent upregulation of NCX1 and proteasomal-dependent downregulation, leaving NCX2 unaffected. NF- $\mathrm{BB}$-dependent NCX1 upregulation occuring during oxygen and glucose deprivation may play a fundamental role in endoplasmic reticulum calcium refilling and may prevent endoplasmic reticulum stress and cell death. In order to distinguish, whether DMOG induced increase of the NCX1 mRNA levels is due to HIF-1 $\alpha$ or $\mathrm{NF}-\kappa \mathrm{B}$, we used $\mathrm{MEF}^{+/+}$and $\mathrm{MEF}^{-/-}$cells. In $\mathrm{MEF}^{+/+}$cells DMOG significantly increased NCX1 mRNA levels compared to control, while in $\mathrm{MEF}^{-/-}$cells, no difference was visible in mRNA levels of the NCX1 in control and DMOG treated groups. This result points to the involvement of HIF$1 \alpha$ in DMOG-induced increase of the NCX1 mRNA. Our observation is in agreement with the work of Valsecchi and coworkers (2011), who demonstrated that the gene coding for the ubiquitous NCX1 protein can be included in the family of genes activated by the transcription factor HIF-1. They proposed that HIF-1 exerts its prosurvival role through the NCX1 upregulation during brain preconditioning.

It was already reported that NCX1 overexpression induced endoplasmic reticulum-related apoptosis in insulin-releasing BRIN-BD11 cells (Diaz-Horta et al. 2002). On the other hand, Wakimoto et al. (2000) reported that targeted disruption of $\mathrm{Na}^{+} / \mathrm{Ca}^{2+}$ exchanger gene leads to cardiomyocyte apoptosis and defects in heartbeat. In our experiments we observed that number of apoptotic cells after DMOG treatment for 3 hours was significantly increased. Also, mRNA levels of the proapoptotic protein caspase 3 was significantly higher in HEK 293 cells subjected to DMOG treatment, compared to control, untreated cells. Thus, to clarify this issue we compared NCX1 protein signal from DMOG-treated, apoptotic (AIK) HEK 293 cells and also from cells, where both AIK and DMOG were applied. We checked whether synergistic effect of both these compounds would be observed, which might point to different transcriptional regulation. We also measured NCX1 promoter activity and calcium transport in DMOG-treated cells, AIK-treated cells and their combination. Although both DMOG and AIK increased NCX1 protein levels, calcium transport and also NCX1 promoter activity, we did not observe a synergistic increase in these parameters after treatment with both compounds. Also, in the experiments with $\mathrm{MEF}^{+/+}$and $\mathrm{MEF}^{-/-}$clearly show that AIK-induced increase of the NCX1 mRNA is not regulated by HIF-1 1 . 
What might be the physiological relevance of increased NCX1 expression in kidney? Using $\mathrm{Na}^{+} / \mathrm{Ca}^{2+}$ exchanger (NCX1)-deficient mice, Yamashita and coworkers (2001) showed that $\mathrm{Ca}^{2+}$ overload via the reverse mode of $\mathrm{Na}^{+} / \mathrm{Ca}^{2+}$ exchange, followed by renal endothelin-1 overproduction, plays an important role in the pathogenesis of ischemia/ reperfusion-induced renal injury. In the kidney, protective effects of KB-R7943 was demonstrated on ischemia/reperfusion-induced acute renal failure, and therefore it was suggested that $\mathrm{Ca}^{2+}$ overload via the reverse mode of NCX1 plays an important role in the pathogenesis of this renal disease (Yamashita et al. 2003).

In summary, we have shown that in HEK 293 cells DMOG treatment for 3 hours significantly increased levels of the NCX1 and this increase is due to HIF-1 regulation. NCX1 mRNA remains increased after the reoxygenation, despite the fact that $\mathrm{pHi}$ returns to control levels after the DMOG wash-out. Both, DMOG and AIK were able to increase number of apoptotic cells. Nevertheless, AIK-induced increase is not triggered by HIF- $1 \alpha$.

Acknowledgements. This publication is the result of the project implementation: TRANSMED, ITMS: 26240120008, supported by the Research \& Development Operational Programme funded by the ERDF; and also by grant VEGA 2/0082/10.

\section{References}

Boscia F., Gala R., Pannaccione A., Secondo A., Scorziello A., Di Renzo G., Annunziato L. (2009): NCX1 expression and functional activity increase in microglia invading the infarct core. Stroke 11, 3608-3617

doi:10.1161/STROKEAHA.109.557439

Calvert J. W., Cahill J., Yamaquchi-Okada M., Zhang J. H. (2006): Oxygen treatment after experimental hypoxia-ischemia in neonatal rats afters the expression of HIF-1 alpha and its downstream target genes. J. Appl. Physiol. 10, 853-865 doi:10.1152/japplphysiol.00268.2006

Correia S. C., Moreira P. I. (2010): Hypoxia-inducible factor 1: a new hope to counteract neurodegeneration? J. Neurochem. $112,1-12$ doi:10.1111/j.1471-4159.2009.06443.x

Cummins E. P., Berra E., Comerford K. M., Ginouves A., Fitzgerald K. T., Seeballuck F., Godson C., Nielsen J. E., Moynagh P., Pouyssegur J., Taylor C. T. (2006): Prolyl hydroxylase-1 negatively regulates IkappaB kinase-beta, giving insight into hypoxia-induced NFkappaB activity. Proc. Natl. Acad. Sci. U.S.A 103, 18154-18159 doi:10.1073/pnas.0602235103

Diaz-Horta O., Kamagate A., Herchuelz A., Van Eylen F. (2002): $\mathrm{Na}+/ \mathrm{Ca} 2+$ exchanger overexpression induces endoplasmic reticulum-related apoptosis and caspase- 12 activation in insulin-releasing BRIN-BD11 cells. Diabetes 51, 1815-1824 doi:10.2337/diabetes.51.6.1815

Eigel B. N., Gursahani H., Hadley R. W. (2004): ROS are required for rapid reactivation of $\mathrm{Na}+/ \mathrm{Ca} 2+$ exchanger in hypoxic reoxygenated guinea pig ventricular myocytes. Am. J. Physiol. Heart. Circ. Physiol. 286, H955-963

doi:10.1152/ajpheart.00721.2003

Fan X., Heijnen C. J., van der Kooij M. A., Groenendaal F., van Bel F. (2009): The role and regulation of hypoxia-inducible factor-1 alpha expression in brain development and neonatal hypoxicischemic brain injury. Brain. Res. Rev. 62, 99-108 doi:10.1016/j.brainresrev.2009.09.006

Hudecova S., Tillinger A., Mravec B., Kvetnansky R., Krizanova O. (2004a): Effect of 6-hydroxydopamine on the gene expression of $\mathrm{Na}+/ \mathrm{Ca} 2+$ exchanger in the rat heart. Gen. Physiol. Biophys. 23, 307-313

Hudecova S., Vadaszova A., Soukup T., Krizanova O. (2004b): Effect of thyroid hormones on the gene expression of calcium transport systems in rat muscle. Life Sci. 75, 923-931 doi:10.1016/j.lfs.2004.01.026

Hudecova S., Kubovcakova L., Kvetnansky R., Kopacek J., Pastorekova S., Novakova M., Knezl V., Tarabova B., Lacinova L., Sulova Z., Breier A., Jurkovicova D., Krizanova O. (2007): Modulation of expression of $\mathrm{Na}+\mathrm{Ca} 2+$ exchanger in heart of rat and mouse under stress. Acta Physiol. (Oxf) 190, 127-136 doi:10.1111/j.1748-1716.2007.01673.x

Jurkovicova D., Kopacek J., Stefanik P., Kubovcakova L., Zahradnikova A. Jr., Zahradnikova A., Pastorekova S., Krizanova O. (2007): Hypoxia modulates gene expression of IP3 receptors in rodent cerebellum. Pflugers Arch. 454, 415-425

Katschinski D. M., Le L., Heinrich D., Wagner K. F., Hofer T., Schindler S. G., Wenger R. H. (2002): Heat induction of the unphosphorylated form of hypoxia-inducible factor-1alpha is dependent on heat shock protein-90 activity. J. Biol. Chem. 277, 9262-9267 doi:10.1074/jbc.M110377200

Li Z., Matsuoka S., Hryshko L. V., Nicoll D. A., Bersohn M. M., Burke E. P., Lifton R. P., Philipson K. D. (1994): Cloning of the NCX2 isoform of the plasma membrane $\mathrm{Na}+\mathrm{Ca} 2+$ exchanger. J. Biol. Chem. 269, 17434-17439

Lowry O. H., Rosebrough N. J., Farr A. L., Randall R. J. (1951): Protein measurement with the Folin phenol reagent. J. Biol. Chem. 193, 265-275

Miyamoto S., Howes A. L., Adams J. W., Dorn G. W. 2nd, Brown J. H. (2005): Ca2+ dysregulation induces mitochondrial depolarization and apoptosis: role of $\mathrm{Na}+/ \mathrm{Ca} 2+$ exchanger and AKT. J. Biol. Chem. 280, 38505-38512 doi:10.1074/jbc.M505223200

Molinaro P., Cuomo O., Pignataro G., Boscia F., Sirabella R., Pannaccione A., Secondo A., Scorziello A., Adornetto A., Gala R., Viggiano D., Sokolow S., Herchuelz A., Schurmans S., Di Renzo G., Annunziato L. (2008): Targeted disruption of $\mathrm{Na}+\mathrm{Ca} 2+$ exchanger 3 (NCX3) gene leads to a worsening of ischemic brain damage. J. Neurosci. 28, 1179-1184 doi:10.1523/JNEUROSCI.4671-07.2008

Nagano T., Osakada M., Ago Y., Koyama Y., Baba A., Maeda S., Takemura M., Matsuda T. (2005): SEA0400, a specific inhibitor of the $\mathrm{Na}+\mathrm{Ca} 2+$ exchanger, attenuates sodium nitroprussideinduced apoptosis in cultured rat microglia. Br. J. Pharmacol. 144, 669-679 doi:10.1038/sj.bjp.0706104 
Nicoll D. A., Quednau B. D., Qui Z., Xia Y. R., Lusis A. J., Philipson K. D. (1996): Cloning of a third mammalian $\mathrm{Na}+\mathrm{Ca} 2+$ exchanger. NCX3. J. Biol. Chem. 271, 24914-24921 doi:10.1074/jbc.271.40.24914

Ryan H. E., Poloni M., McNulty W., Elson D., Gassmann M., Arbeit J. M., Johnson R. S. (2000): Hypoxia-inducible factor-1alpha is a positive factor in solid tumor growth. Cancer Res. 60, 4010-4015

Ryan S., Taylor C. T., McNicholas W. T. (2005): Selective activation of inflammatory pathways by intermittent hypoxia in obstructive sleep apnea syndrome. Circ. 112, 2660-2667 doi:10.1161/CIRCULATIONAHA.105.556746

Seagroves T. N., Ryan H. E., Lu H., Wouters B. G., Knapp M., Thibault P., Laderoute K., Johnson R. S. (2001): Transcription factor HIF-1 is a necessary mediator of the pasteur effect in mammalian cells. Mol. Cell. Biol. 21, 3436-3444 doi:10.1128/MCB.21.10.3436-3444.2001

Semenza G. L. (2000): HIF-1: mediator of physiological and pathophysiological responses to hypoxia. J. Appl. Physiol. 88, 1474-1480

Shono Y., Kamouchi M., Kitazono T., Kuroda J., Nakamura K., Hagiwara N., Ooboshi H., Ibayashi S., Iida M. (2010): Change in pHi causes the toxic Ca2+entry via NCX1 in neuron- and glia-derived cells. Cell. Mol. Neurobiol. 30, $453-460$ doi:10.1007/s10571-009-9470-7

Siddiq A., Aminova L. R., Ratan R. R. (2008): Prolyl 4-hydroxylase activity-responsive transcription factors: from hydroxylation to gene expression and neuroprotection. Front. Biosci. 13, 2875-2887 doi: $10.2741 / 2892$

Sirabella R., Secondo A., Pannaccione A., Scorziello A., Valsecchi V., Adornetto A., Bilo L., di Renzo G., Annunziato L. (2009): Anoxia-induced NF-kappaB-dependent upregulation of NCX1 contributes to $\mathrm{Ca} 2+$ refiling into endoplasmic reticulum in cortical neurons. Stroke 40, 922-929 doi:10.1161/STROKEAHA.108.531962

Taylor C. T., Dzus A. L., Colgan S. P. (1998): Autocrine regulation of epithelial permeability by hypoxia: role for polarized release of tumor necrosis factor alpha. Gastroenterol. 114, 657-668 doi:10.1016/S0016-5085(98)70579-7

Valsecchi V., Pignataro G., Del Prete A., Sirabella R., Matrone C., Boscia F., Scorziello A., Sisalli M. J., Esposito E., Zambrano N., Di Renzo G., Annunziato L. (2011): NCX1 is a novel target gene for hypoxia-inducible factor- 1 in ischemic brain preconditioning. Stroke 42, 754-763 doi:10.1161/STROKEAHA.110.597583

Wakimoto K., Kobayashi K., Kuro O. M., Yao A., Iwamoto T, Yanaka N., Kita S., Nishida A., Azuma S., Toyoda Y., Omori K., Imahie H., Oka T., Kudoh S., Kohmoto O., Yazaki Y., Shigekawa M., Imai Y., Nabeshima Y., Komuro I. (2000): Targeted disruption of $\mathrm{Na}+/ \mathrm{Ca} 2+$ exchanger gene leads to cardiomyocyte apoptosis and defects in heartbeat. J. Biol. Chem. 275, 36991-36998 doi:10.1074/jbc.M004035200

Yamashita J., Itoh M., Kuro T., Kobayashi Y., Ogata M., Takaoka M., Matsumura Y. (2001): Pre-ischemic or post-ischemic treatment with a novel $\mathrm{Na}+\mathrm{Ca} 2+$ exchange inhibitor, KB-R7943, shows renal protective effects in rats with ischemic acute renal failure. J. Pharmacol. Exp. Ther. 296, 412-419

Yamashita J., Kita S., Iwamoto T., Ogata M., Takaoka M., Tazawa N., Nishikawa M., Wakimoto K., Shigekawa M., Komuro I., Matsumura Y. (2003): Attenuation of ischemia/reperfusioninduced renal injury in mice deficient in $\mathrm{Na}+\mathrm{Ca} 2+$ exchanger. J. Pharmacol. Exp. Ther. 304, 284-293 doi:10.1124/jpet.102.039024

Received: November 2, 2010

Final version accepted: April 4, 2011 